\title{
Suppression of hepatitis B virus replication mediated by hepatitis A-induced cytokine production
}

van Nunen AB, Pontesilli O, Uytdehaag F, Osterhaus ADME, de Man RA. Suppression of hepatitis B virus replication mediated by hepatitis A-induced cytokine production.

Liver 2001: 21: 45-49. (C) Munksgaard, 2001

Abstract: Background: Acute hepatitis A virus (HAV) infection can cause severe hepatitis especially in patients with underlying chronic liver disease. In patients with pre-existing chronic hepatitis B (HBV) acute HAV infection can suppress HBV replication. The exact mechanism of HBV suppression during acute HAV infection is still a subject of debate. One mechanism may be the production of HAV infection-induced cytokines leading to suppression of HBV replication and viral clearance. Aim: To evaluate cytokine production and $\mathrm{HBV}$-specific lympho-proliferative responses (LPR) during acute HAV infection in a patient with chronic HBV infection-clearing markers of active HBV replication. Design: Early detection of a case of acute HAV infection in an HBeAg-positive, HBV DNA-positive chronic HBV patient treated with lamivudine. Results: At the time of HAV infection a sharp peak in the gamma-interferon (IFN- $\gamma$ ) level occurred just before the rise in serum transaminase activity. This was subsequently followed by a decrease in HBV DNA and HBeAg below the limit of detection of the assay. However the HBV-specific T-cell response was not modified. After resolution of the acute HAV infection and withdrawal of antiviral therapy HBV replication relapsed. Conclusion: The sharp rise in IFN- $\gamma$ production mediated by the acute HAV infection may be pivotal in the suppression of HBV replication in chronic hepatitis B.

\author{
Andeltje B. van Nunen', \\ Oscar Pontesilli², Fons Uytdehaag², \\ Albert D. M. E. Osterhaus ${ }^{2}$ and \\ Robert A. de Man'
}

Departments of ${ }^{1}$ Hepatogastroenterology and ${ }^{2}$ Virology, Erasmus University Hospital Rotterdam, Rotterdam, The Netherlands

Key words: chronic hepatitis $B$ - acute hepatitis A - alpha interferon - gamma-interferon - TNFalpha - IL-10 - IL-12 - lympho-proliferative response

R. A. de Man MD, PhD, Dept. of Hepatogastroenterology, Room Ca 326, Erasmus University Hospital Rotterdam, P.0. Box 2040, 3000 CA Rotterdam, The Netherlands Tel: +3110463 3793. Fax: +31104365916 e-mail: devlaming@mdl.azr.nl

Received 23 May, accepted 26 September 2000
After acute hepatitis B virus (HBV) infection 5$10 \%$ of all adult patients become chronically infected; the mechanism of the viral persistence in this minority of patients remains unclear. In patients with an acute self-limiting HBV infection a vigorous T-lymphocyte response to the core antigen and a weaker response to the surface antigen are observed $(1,2)$. It is suggested that the production of Th1-type pro-inflammatory cytokines (gamma-interferon (IFN- $\gamma$ ) interleukin-2 (IL-2) and tumour necrosis factor-alpha $(\mathrm{TNF}-\alpha)$ ) is mainly instrumental in inducing viral clearance (3). Viral persistence on the other hand is associated with T-cell hyporesponsiveness possibly due to exhaustion or paralysis of the immune system due to overwhelming antigen presentation $(1,4)$. Recombinant alpha interferon therapy successfully inhibits viral replication in about $30 \%$ of the patients with chronic hepatitis B by means of the di- rect antiviral effects of the drug or by inducing an HBV-specific immune response (5).

Hepatitis A virus (HAV) is transmitted enterally. In highly endemic areas it causes a mild self-limiting hepatitis among young children. In countries of low endemicity infection occurs at an older age. This is associated with a much higher case fatality rate especially among adults over 40 years of age (6). In patients with underlying chronic liver diseases such as chronic hepatitis C, HAV infection can lead to fulminant hepatitis and death $(7,8)$.

Data on the impact of HAV infection on chronic HBV are contradictory (7-9). HAV superinfection has been reported to have an inhibitory effect on HBV replication during the acute phase of HAV. Several antiviral mechanisms have been postulated to explain the drop in HBV protein production: a direct effect of the reduction in target cells following hepatic necrosis or viral interference, or an in- 


\section{Van Nunen et al.}

direct effect due to HAV-induced cytokine production (9-13).

During an HAV outbreak among homosexual men in the Rotterdam area we studied a chronic hepatitis B patient during an early phase of acute HAV infection in detail.

\section{Materials and methods}

Viral serology

Diagnosis of acute HAV infection was based on a highly positive IgM-anti HAV test (IMX Abbott Chicago, IL). Co-infections with CMV EBV HDV and HIV were excluded by standard serology. Acute HCV infection was excluded by PCR.

HBV DNA was measured by liquid hybridization (Digene II, Murex, UK) and, if negative, by PCR (detection limit 400 genome equivalents per $\mathrm{ml}$ (gen Equiv/ml) based on the Eurohep standard). HBeAg (IMX, Abbott) and HBsAg (AxSYM HBsAg, Abbott) were measured quantitatively and expressed in Paul Ehrlich Units.

\section{Measurement of serum cytokine levels}

Sequential serum samples before and during the acute hepatitis episode have been tested for levels of circulating IFN- $\alpha$, IFN- $\gamma$, IL-10, IL-12, and TNF- $\alpha$ by means of the standard sandwich ELISA technique. Antibodies for coating and detection, and ELISA reagents were obtained from the following: HyCult biotechnology, Uden, The Netherlands (anti-IFN- $\alpha$ ); Medgenix Diagnostics, Fleurus, Belgium (anti-IFN- $\gamma$ ); Pharmingen, San Diego, CA, USA (anti-IL10); R\&D Systems, Minneapolis, MN, USA (anti-IL12); and CLB, Amsterdam, The Netherlands (TNF- $\alpha$ ). Lower detection limits in each assay were: IFN- $\alpha, 50 \mathrm{pg} / \mathrm{ml}$; IFN- $\gamma, 10 \mathrm{pg} / \mathrm{ml}$; IL-10, $20 \mathrm{pg} / \mathrm{ml}$; IL-12, 80 pg/ml; TNF- $\alpha, 4 \mathrm{pg} / \mathrm{ml}$.

\section{Antigens}

Recombinant C-terminal truncated $\mathrm{HBcAg}$ particles (146aa) expressed in E. coli (American Research Products, Belmont, MA, USA; cat no.123069, batch r-HBcAg-e-CIT-0070) were used in lymphocyte stimulation assays. As control antigen, recombinant HCV NS3 protein, also expressed in E. coli (American Research Products, cat. no.1200117, batch 9812ns3) was used. Recombinant pre$\mathrm{S}_{1^{-}}$and pre-S $\mathrm{S}_{2}$-containing $\mathrm{HBsAg}$ particles, expressed in Chinese hamster ovary (CHO) cells, were obtained from Dr Reinhard Gluck (Swiss

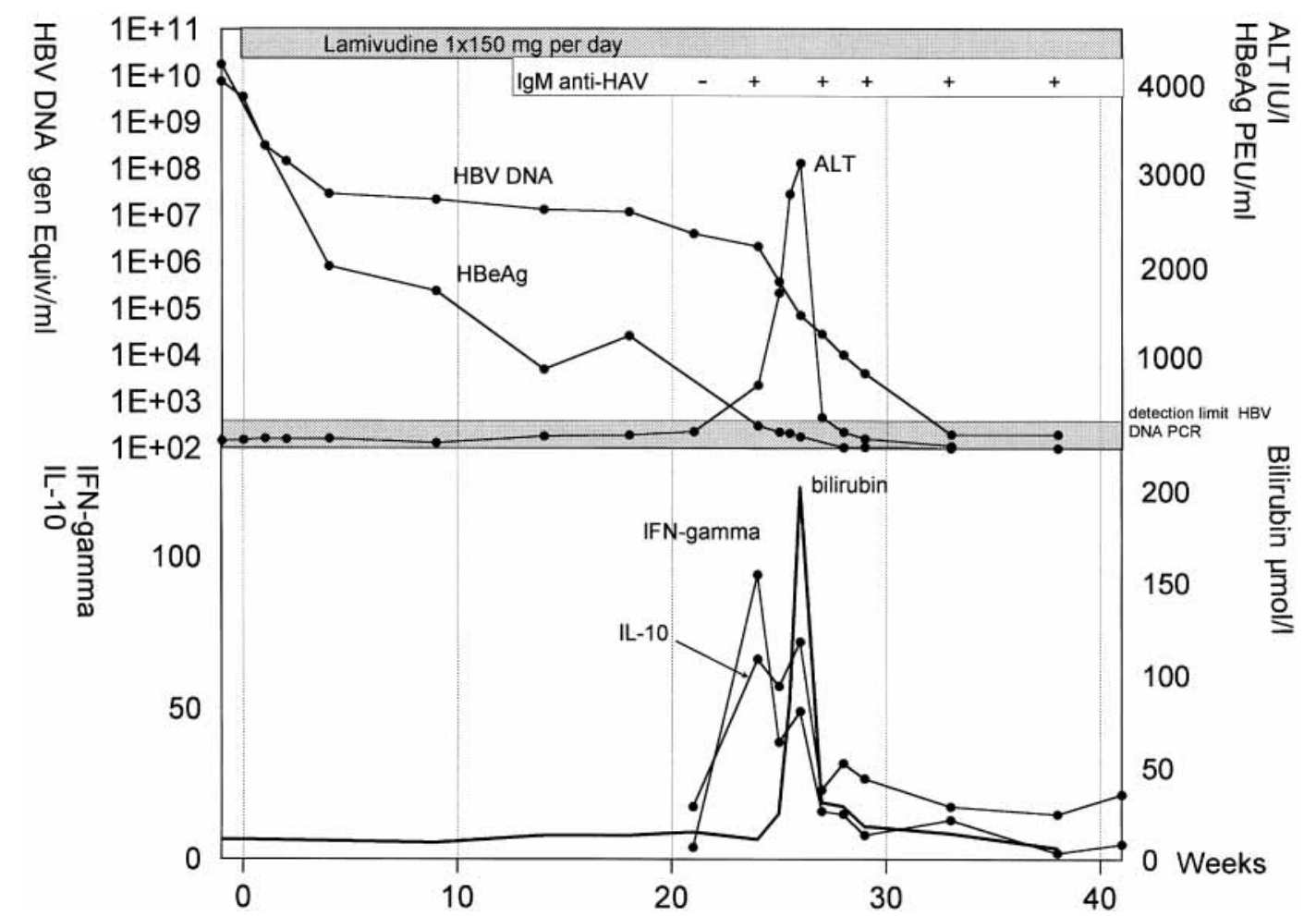

Fig. 1. Patient with chronic hepatitis B infected with HAV during lamivudine treatment. A sudden drop in HBV DNA was observed in combination with a hepatitis flare followed by loss of $\mathrm{HBeAg}$. An interferon-gamma peak preceded the rise in serum transaminase activity. 


\section{Suppression of HBV replication induced by acute HAV infection}

Serum and Vaccine Institute Berne, Berne, Switzerland).

\section{In vitro lymphocyte proliferation assays}

Ag-specific lymphocyte proliferative response (LPR) was measured retrospectively culturing $10^{5}$ thawed peripheral blood mononuclear cells (PBMC) in four replicate round-bottom microtitre wells for 7 days in $0.1 \mathrm{ml}$ RPMI-1640 supplemented with antibiotics and 10\% human pooled serum in the presence of one of the above described antigens. Optimal Ag concentration was determined as $2 \mu \mathrm{g} / \mathrm{ml}$ according to titrations performed on PBMC from patients with acute hepatitis B and healthy blood donors, either HBsAgvaccinated or not. $\left[{ }^{3} \mathrm{H}\right]$-Thymidine (specific activity $5 \mathrm{mCi} / \mathrm{mmol}$ ) was added for the last $20 \mathrm{~h}$ of culture and the incorporated radioactivity measured in a $\beta$-scintillation counter. Results were expressed as counts per minute (cpm) and the lymphocyte stimulation index (LSI) was calculated as the ratio between median cpm in the $\mathrm{HBcAg}$ - or $\mathrm{HBsAg}$ containing cultures and median cpm of cultures containing HCV NS3 or no added Ag, respectively. The 99th percentile of $\mathrm{HBcAg}$-specific SI in 10 healthy blood donors was 2.29 . For practical purposes, specific LPR was scored positive when $\mathrm{LSI}>3$.

\section{Results}

A 33-year-old homosexual man was known to have been $\mathrm{HBeAg}$-positive since 1995 . He was a nonresponder to a previous 4-month course of alpha interferon in 1996. Lamivudine $(150 \mathrm{mg}$ once daily) was started in August 1997 and the patient was included in a standardised monthly follow-up protocol. The initial drop in HBV DNA ceased after 8 weeks of treatment but HBV DNA remained detectable at levels around $10^{7}-10^{6}$ gen Equiv/ml (Fig. 1).

After 24 weeks of lamivudine therapy ALAT, ASAT and bilirubin rose to peak levels of 3061 U/l, $1764 \mathrm{U} / 1$ and $202 \mu \mathrm{mol} / 1$, respectively. He was jaundiced and complained of malaise, lack of appetite and fatigue. There was neither alcohol nor drug abuse. The differential diagnosis included lamivudine resistance, drug toxicity, spontaneous clearance of hepatitis $\mathrm{B}$, and a post-lamivudine flare due to non-compliance or superinfection with HAV, HCV or HDV.

Compliance with his lamivudine medication was demonstrated excluding a lamivudine-withdrawal flare. He did not use nor had ever used other drugs. No evidence of HCV or HDV was found. A YMDD analysis showed wild-type hepatitis B virus.
Table I. HBcAg-specific LPR of the control population versus the LPR over time of the acute HAV-infected CHB patient

\begin{tabular}{llll}
\hline & & HBc-LSI & LSI SE \\
\hline \multirow{6}{*}{ Controls } & Healthy donors $(n=10)$ & 1.3700 & 0.1400 \\
& AHB $(n=11)$ & 4.2100 & 0.9700 \\
& CHB $(n=16)$ & 2.1400 & 0.2900 \\
Patient & Week 0 (start lamivudine) & 2.8600 & \\
& Week 4 & 3.7600 & \\
& Week 48 (after acute HAV) & 4.9000 & \\
\hline
\end{tabular}

AHB: acute hepatitis B. CHB: chronic hepatitis B. SE: standard error.

Extensive virological testing documented an acute HAV superinfection. IgM anti-HAV was detectable in serum at the moment serum transaminase activity started to increase. Peak serum levels of naturally produced IFN- $\gamma$, but also IL-10, were measurable just before the rise in serum transaminase activity and the subsequent drop in HBV DNA levels (Fig. 1). In these samples the levels of IFN$\alpha$, TNF- $\alpha$ and IL-12 were below the level of detection. The proliferative response of PBMC's against the hepatitis B core antigen was already detectable before the acute hepatitis, after lamivudine therapy was started and showed no significant change after the acute HAV infection (Table 1). No HBsAg-specific response could be measured in these samples.

During the next 2 months HBV DNA dropped further below the level of PCR detection. $\mathrm{HBeAg}$ and anti-HBe reached borderline values, $\mathrm{HBsAg}$ remained detectable at very low levels and serum transaminases dropped to normal.

After seroconversion alpha interferon therapy was started to induce a sustained $\mathrm{HBeAg}$ seroconversion with detectable anti-HBe antibodies. After 8 weeks of combination therapy lamivudine was withdrawn; HBV DNA subsequently became detectable. After 12 weeks of IFN monotherapy anti$\mathrm{HBe}$ antibodies were detectable; IFN was given for a total period of 20 weeks. However, after its withdrawal, HBeAg relapsed.

\section{Discussion}

Acute hepatitis A infection has been reported to suppress hepatitis B viral replication in several cases (9-13). In acute hepatitis A lysis of infected hepatocytes is mainly a T-cell-mediated cytotoxic mechanism rather than a direct cytopathic effect of the virus (14-16). It has been suggested that massive necrosis of infected hepatocytes leads to the decrease in HBV DNA (11-13). Hepatitis A caused massive necrosis of infected hepatocytes in our patient, resulting in elevated transaminase activity followed by clearance of HBV DNA and $\mathrm{HBeAg}$. However, it is unlikely that cell necrosis of 
HBV-infected hepatocytes mediated by HAV-specific cytotoxic $\mathrm{T}$ lymphocytes eliminates all HBV-infected hepatocytes.

The contribution of noncytolytic antiviral effects may be of major importance for viral clearance in HBV (17). HAV-induced cytokine production is one of the mechanisms that might cause HAV-induced suppression of HBV replication (11, 18). IgM anti-HAV positivity coincided with the high production of IFN- $\gamma$ followed by inhibition of HBV DNA replication. In vitro data suggest that IFN- $\gamma$ is the main effective mediator in acute HAV infection. The effects occur at three levels: stimulation of HLA antigen expression, direct virus-specific antiviral effects and immunomodulatory effects (19). Acute self-limited HBV is probably also mediated by predominantly Th1 cytokine production, especially of IFN- $\gamma$ (3). Furthermore, increased IL-12 levels are associated with $\mathrm{HBeAg}$ seroconversion (20).

In this case HAV-specific IFN- $\gamma$, focused on infected hepatocytes, probably caused the drop in HBV DNA. An IFN- $\alpha$ peak, as found by Davis et al. (11), could not be confirmed; TNF- $\alpha$ and IL12 were also below the level of detection. At the same time the production of IL-10, an immuneregulating and anti-inflammatory Th2-cytokine, was stimulated, probably contributing to the selflimitation of the response.

Induction of an $\mathrm{HBV}$-specific response would possibly prevent relapse of the HBV infection. Chronic HBV is associated with a weak and ineffective antiviral T-cell response to nucleocapside antigens ( $\mathrm{HBcAg}$ and $\mathrm{HBeAg}$ ) in contrast to the strong response in acute HBV infection $(1,3)$. In acute exacerbations, spontaneous clearance and response to alpha interferon therapy, a re-activated $\mathrm{T}$ cell response is measurable, necessary for viral elimination (21-23). Restoration of nucleocapsidespecific $\mathrm{T}$ cell response has been described also during lamivudine treatment (4), but the underlying mechanism and its clinical meaning are still unclear. Studies in a transgenic mouse model suggest a relevant role for non-cytolytic IFN- $\gamma$ and TNF$\alpha$-mediated suppression of HBV genome expression exerted by HBsAg-specific CTLs (24).

In our patient there was already a pre-existing weak LPR against $\mathrm{HBcAg}$ when lamivudine therapy was started. As expected no response to the surface antigen was detectable. The LPR did not increase after the acute HAV infection, when measured in peripheral blood. This does not exclude an increased response because of the possible compartmentalization of stimulated T-cells in the liver (2). However this is not very likely in our patient in view of his relapse after withdrawal of therapy.

$\mathrm{HAV}$-induced production of IFN- $\gamma$ probably in- duced HBV DNA and HBeAg negativity. However, this was not combined with stimulation of an HBV-specific T-cell memory which is probably necessary to maintain $\mathrm{HBe}$-seroconversion and protection against HBV relapse. In conclusion we think that our observations may contain important implications for specific immunotherapy for chronic HBV patients on nucleoside analogue therapy.

\section{References}

1. Chisari F V, Ferrari C. Hepatitis B virus immunopathogenesis. Ann Rev Immunol 1995; 13: 29-60.

2. Ferrari C, Penna A, Bertoletti A, et al. Cellular immune response to hepatitis $B$ virus-encoded antigens in acute and chronic hepatitis B infection. J Immunol 1990; 145: 34429.

3. Penna A, Del Prete G, Cavalli A, et al. Predominant Thelper 1 cytokine profile of hepatitis B virus nucleocapsidespecific $\mathrm{T}$ cells in acute self-limited hepatitis B. Hepatology 1997; 25: 1022-7.

4. Boni C, Bertoletti A, Penna A, et al. Lamivudine treatment can restore $T$ cell responsiveness in chronic hepatitis B. J Clin Invest 1998; 102: 868-75.

5. Wong D K H, Cheung A M, O'Rourke K, Naylor CD, Detsky A S, HeAthсоте J. Effect of alpha-interferon treatment in chronic hepatitis B e antigen-positive chronic hepatitis B. Ann Intern Med. 1993; 119: 312-23.

6. HADler S C. Global impact of hepatitis A virus infection: changing patterns. In: Hollinger F B, Lemon S M, Margolis H, eds. Viral hepatitis and liver disease. Baltimore: Williams \& Williams, 1991: 14-20.

7. Vento S, Garofano T, Renzini C, et al. Fulminant hepatitis associated with hepatitis $A$ virus superinfection in patients with chronic hepatitis C. N Engl J Med 1998; 338: 286-90.

8. KEEFFE E. Is hepatitis A more severe in patients with chronic hepatitis B and other chronic liver diseases? Am J Gastroenterol 1995; 90: 201-5.

9. Tassopoulos N, Papaevangelou G, Roumeliotou-KarayANNIS A, et al. Double infections with hepatitis A and B viruses. Liver 1985; 5: 348-53.

10. Viola L A, Coleman J C, Barrison I G, Murray-Lyon I M. The clinical course of acute type A hepatitis in chronic HBsAg carriers: a report of three cases. Postgrad Med J 1982; 58: 80-1.

11. Davis G, Hoofnagle J, Waggoner J. Acute type A hepatitis during chronic hepatitis B virus infection: association of depressed hepatitis $\mathrm{B}$ virus replication with appearance of endogenous alpha interferon. J Med Virol 1984; 14: 1417.

12. Conteas C, Kao H, Rakela J, Weliky B. Acute type A hepatitis in three patients with chronic HBV infection. Dig Dis Sci 1983; 28: 684-6.

13. Wang J-Y, LeE S-D, Tsai Y-T, Lo K-J, Chiang BN. Fulminant hepatitis A in chronic HBV carrier. Dig Dis Sci 1986; 31: 109-11.

14. Vallbracht A, Maier K, Stierhof Y D, Wiedmann K H, Flehmig B, Fleischer B. Liver-derived cytotoxic T cells in hepatitis A virus infection. J Infect Dis 1989; 160: 209-17.

15. Lemon S M, Ping L H, DAY S, et al. Immunobiology of hepatitis A virus. Viral hepatitis and liver disease. Baltimore: Williams \& Williams, 1991: 14-20.

16. Kurane I, Binn L N, Bancroft W H, Ennis F A. Human lymphocyte responses to hepatitis A virus-infected cells: in- 


\section{Suppression of HBV replication induced by acute HAV infection}

terferon production and lysis of infected cells. J Immunol 1985; 135: 2140-4.

17. Guidotti L G, Rochford R, Chung J, Shapiro M, PurCELL R, CHISARI FV. Viral clearance without destruction of infected cells during acute HBV infection. Science 1999; 284: 825-9.

18. Tsiquaye K, Harrison T J, Portmann B, Hu S, ZuckerMAN A J. Acute hepatitis A infection in hepatitis B chimpanzee carriers. Hepatology 1984; 4: 504-9.

19. Maier K, Gabriel P, Koscielniak E, et al. Human gamma interferon production by cytotoxic $\mathrm{T}$ lymphocytes sensitized during hepatitis A virus infection. J Virol 1988; 62: 3756-63.

20. Rossol S, Marinos G, Garucci P, Singer M V, Williams $\mathrm{R}$, NaOumov NV. Interleukin-12 induction of TH1 cytokines is important for viral clearance in chronic hepatitis B. J Clin Invest 1997; 99: 3025-33.
21. Tsai S L, Chen P J, Lai P M, et al. Acute exacerbations of chronic type $\mathrm{B}$ hepatitis are accompanied by increased $\mathrm{T}$ cell responses to hepatitis $\mathrm{B}$ core and e antigens. J Clin Invest 1992; 89: 87-96.

22. Jung M C, Diepolder H M, Spengler U, et al. Activation of a heterogeneous hepatitis $\mathrm{B}(\mathrm{HB})$ core and e antigen specific $\mathrm{CD} 4+\mathrm{T}$-cell population during seroconversion to anti$\mathrm{HBe}$ and anti-HBs in hepatitis B virus infection. J Virol 1995; 69: 3358-68.

23. Rehermann B, Hoofnagle J H, Chisari F V. Cytotoxic T lymphocyte responsiveness after resolution of chronic hepatitis B virus infection. J Clin Invest 1996; 97: 1655-65.

24. Guidotti L G, Ando K, Hobbs M V, et al. Cytotoxic T lymphocytes inhibit hepatitis B virus gene expression by a noncytolytic mechanism in transgenic mice. Proc Natl Acad Sci USA 1994; 91: 3764-8. 